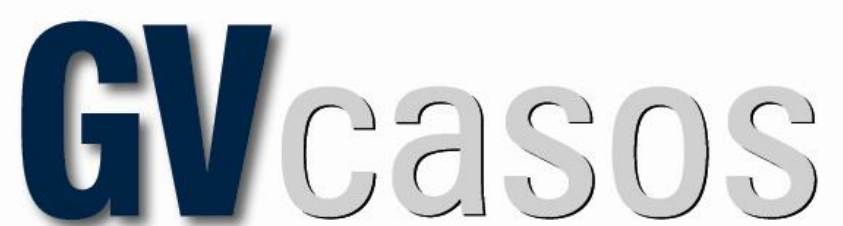

DOI: http://dx.doi.org/10.12660/gvcasosv6n1c6

\title{
A INTERNACIONALIZAÇÃO DA MANIFESTO GAME STUDIO ${ }^{1}$ The Internationalization of Manifesto Game Studio
}

GIL BARRTEO DE GOES - gildegoes@ gmail.com

Pontifícia Universidade Católica do Rio de Janeiro - Rio de Janeiro, RJ, Brasil

JORGE BRANTES FERREIRA - jorgebf@ gmail.com

Pontifícia Universidade Católica do Rio de Janeiro - Rio de Janeiro, RJ, Brasil

Submissão: 16/09/2015 | Aprovação: 22/03/2016

\begin{abstract}
Resumo
O processo de internacionalização da Manifesto Game Studio apresenta características que são comuns às empresas de jogos eletrônicos no Brasil: devido a dificuldades na exploração do mercado nacional de jogos, elas acabam buscando mercados internacionais. Fundada em 2005 e contando atualmente com 25 funcionários, a Manifesto enfrenta o desafio de continuar crescendo nesse mercado.
\end{abstract}

Palavras-chave: Negócios internacionais, empreendedorismo, outsourcing

\begin{abstract}
The internationalization process of Manifesto Game Studio has some characteristics that are common to other Brazilian game companies. Due to difficulties in the national game market, they end up looking for international markets. Founded in 2005 and currently with 25 employees, Manifesto faces the challenge of continuing to grow internationally.
\end{abstract}

Kewwords: Internationalization, medical services, medical tourism

\section{Contexto}

Localizada em Recife, a Manifesto Game Studio é uma empresa de entretenimento digital, que atua no segmento de jogos eletrônicos, tendo iniciado suas atividades em 2005. A empresa foi criada com o propósito de desenvolver produtos, inicialmente browser games e, depois, downloadable casual games, com foco principalmente no mercado internacional. Após alguns anos de atividade, no entanto, passou a trabalhar também na prestação de serviços associados a jogos, com produção para terceiros no Brasil e no exterior. A estrutura da empresa contava, em 2013, com 25 funcionários no Brasil. Em torno de $10 \%$ a $15 \%$ do faturamento total, nos últimos anos, era proveniente de exportação de serviços para clientes internacionais.

Os principais serviços desenvolvidos pela empresa eram games para marcas ${ }^{2}$, "gameficação" e outsourcing (terceirização). Das três áreas de prestação de serviços, a de games

\footnotetext{
${ }^{1} \mathrm{O}$ presente trabalho foi realizado com o apoio da Agência Brasileira de Promoção de Exportações e Investimentos (Apex-Brasil).

${ }^{2}$ Games para marcas (games for brands) é a utilização de jogos eletrônicos para promover uma determinada marca, produto ou serviço.

3 "Gameficação" é criação de jogos para as mais diversas áreas das empresas e outras organizações, com o intuito de transformar atividades rotineiras em experiências mais divertidas e motivadoras.
} 
para marcas e a de "gameficação" se destinavam ao mercado brasileiro, enquanto a de outsourcing era realizada para empresas no exterior. O desenvolvimento de games para marcas, dentro da categoria advergames, estava ligado à atividade promocional de empresas clientes. Já no caso da "gameficação", a empresa atuava revendo determinados serviços e sistemas de empresas, buscando transformá-los em experiências mais prazerosas para seus clientes e funcionários, por meio da criação de games. Na área de outsourcing, a Manifesto atuava em parceria com empresas estrangeiras, como parte da equipe de desenvolvimento de um game.

Vicente Vieira Filho, um dos fundadores da empresa e seu diretor de negócios, preocupavase com os problemas vivenciados pela empresa em seu processo de internacionalização e indagavase de que forma esses obstáculos poderiam ser minimizados. Em particular, percebia a necessidade de elaborar um plano de negócios que contemplasse o desenvolvimento da imagem da empresa e a questão de captação de novos clientes.

\section{Indústria de games}

A cadeia produtiva do setor de games inclui desenvolvedores, publishers, proprietários de console e varejistas, como representado na Figura 1.

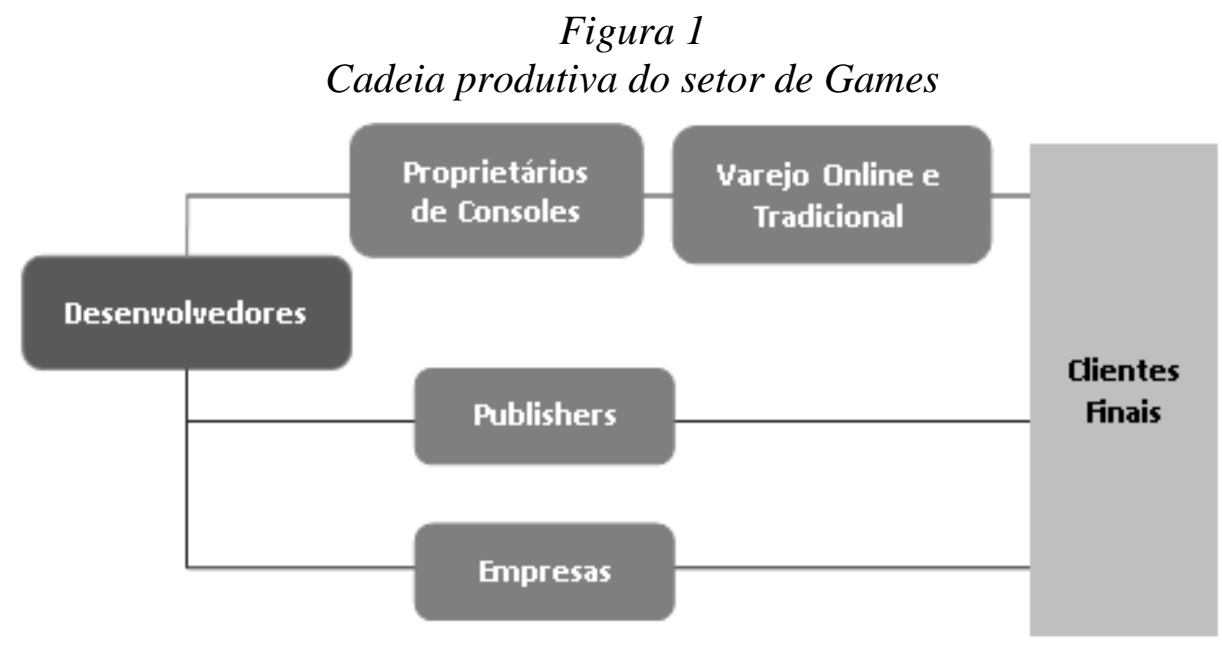

Fonte: elaboração prórpia

Desenvolvedores - Podem ser empresas ou indivíduos, que produzem jogos por encomenda ou para colocá-los no mercado. As empresas desenvolvedoras de software podem ser classificadas em três tipos, em função de sua relação com os publishers: (i) Estúdio próprio do publisher; (ii) Desenvolvedoras controladas por um publisher; (iii) Desenvolvedoras que produzem games exclusivos para um publisher; e (iv) Desenvolvedoras que produzem para um publisher sem contrato de exclusividade. De acordo com pesquisa da Associação Brasileira das Desenvolvedoras de Jogos Eletrônicos (Abragames, 2008), havia 560 profissionais altamente capacitados no Brasil, atuando em 42 empresas produtoras de softwares para jogos eletrônicos. Em pesquisa mais recente feita também pela Abragames, o número de empresas desenvolvedoras de games já estava em 200.

Publishers - São empresas que publicam games, sejam eles desenvolvidos pelo próprio publisher ou por outras empresas. Os publishers podem exercer as seguintes funções: (i) distribuição (física ou digital) do jogo, responsabilizando-se por tudo o que for necessário para o jogo chegar aos consumidores potenciais; (ii) financiamento do desenvolvimento do jogo; (iii) escolha de que títulos serão produzidos, tomando como base estudos de mercado; (iv) definição de estratégias de marketing e comunicação; e (v) realização de procedimentos de QA (Quality Assurance) para testar o jogo e garantir que as expectativas foram atingidas. 
Proprietários de consoles - O mercado de consoles é dominado por três empresas: Sony, Nintendo e Microsoft. Tanto a Sony quanto a Nintendo são empresas fabricantes de manufaturados, enquanto a Microsoft pertence ao setor de software. A convergência digital levou a que empresas de diferentes setores e com competências muito distintas pudessem competir em igualdade de condições no mesmo setor. É interessante observar que as estatísticas, no Brasil, relativas à participação no mercado de consoles de videogames são pouco confiáveis, uma vez que, dependendo da fonte, diferentes proprietárias de consoles aparecem liderando o mercado. Isso se deve a dois fatores: de um lado, a existência de aparelhos de videogame trazidos ao País de modo não oficial (contrabando ou em bagagem de viajantes), ou ainda à existência de mercado de revenda de aparelhos de segunda mão.

Varejo on-line e tradicional - $\mathrm{O}$ varejo tradicional e as lojas virtuais de varejistas tradicionais também se constituem em canais de distribuição de jogos para consoles. Além disso, assiste-se à transferência do varejo de jogos eletrônicos para redes sociais, lojas virtuais de aplicativos e sites de jogos on-line.

\section{Mercado de games}

O mercado mundial de games passou de 25 bilhões de dólares em 2004 para 59 bilhões em 2009, com uma taxa de crescimento anual composta de 16,5\%. No entanto, com a crise econômica que atingiu predominantemente os países desenvolvidos, essa taxa não se sustentou. Assim, o mercado mundial de games atingiu 63 bilhões em 2012, estimando-se que chegaria a 87 bilhões em 2017, a uma taxa de crescimento anual composta de 6,5\%. ${ }^{4}$ Os três principais mercados são Estados Unidos, Japão e China, em termos de receitas geradas pela venda de games (Anexo 1). Como se pode observar no gráfico, os três mercados mostram forte tendência ascendente, embora o mercado americano tenha sofrido uma queda brusca entre 2011 e 2012.

A previsão da PwC (2013) é de que os jogos em plataformas de dispositivos móveis cresçam a taxas mais rápidas do que aqueles nas demais plataformas, principalmente em função da crescente adoção de smartphones em todo o mundo. Assim, a expectativa é de que o segmento cresça nos próximos anos a uma taxa composta anual de aproximadamente 10\%, passando de 8,8 bilhões de dólares em 2012 para 14 bilhões em 2017. Prevê-se um crescimento também significativo no segmento de consoles de 25 bilhões de dólares em 2012 para 31 bilhões em 2017, a uma taxa anual composta de 5\%. Esse crescimento deve ocorrer em função de lançamentos de novas versões tecnologicamente mais avançadas de consoles pelas três líderes. Já no segmento de games para computadores pessoais, a expectativa é de pouco crescimento.

O mercado brasileiro de games é considerado um dos cinco maiores do mundo, tendo movimentado 420 milhões de dólares em 2011, com uma taxa de crescimento anual composta de 8,8\%. Além disso, estima-se que cerca de um quarto dos brasileiros sejam usuários de jogos eletrônicos. A distribuição por plataforma é a seguinte: $67 \%$ dos jogadores utilizam o console, $42 \%$ utilizam computadores, $16 \%$ usam celulares e $1 \%$ joga em tablets. ${ }^{5}$

No que se refere ao outsourcing da produção de games, há diversas possibilidades de oferta de serviços de outsourcing em países emergentes como o Brasil. Embora muitos serviços de outsourcing possam ser prestados por empresas em países como a Índia, que geralmente possuem custos mais baixos que o Brasil, as empresas que contratam serviços de alta complexidade em diferentes países não estão apenas preocupadas em obter o menor custo. Além do custo, elas

\footnotetext{
${ }^{4}$ PwC (2013). Global entertainment and media outlook: 2013-2017. Recuperado de http://www.pwc.com/gx/en/globalentertainment-media-outlook/segment-insights/video-games.jhtml

${ }^{5}$ Lara, G. (2012, Outubro 10). Brasil é o $4^{\circ}$ maior consumidor mundial de games. O Estado de S. Paulo. Recuperado de http://economia.estadao.com.br/noticias/economia,brasil-e-4-maior-consumidor-mundial-de-games, 130283,0.htm
} 
buscam mão de obra mais qualificada, capaz de compreender o contexto dos seus negócios, $e$ também necessitam de uma frequência maior de interação.

Nos grandes centros brasileiros, há expressivo número de jovens com alta qualificação e que falam inglês. Essa mão de obra é capaz de desenvolver todo tipo de atividade, como o desenvolvimento de games, por um custo mais baixo que em países mais desenvolvidos. O Brasil tem a maior parte dos programadores Java em todo o mundo e é o segundo maior em número de programadores de mainframes (COBOL), segundo a Brasscom. Outro fator que favorece os serviços de outsourcing é a proximidade dos fusos horários da América do Sul em relação aos da América do Norte. Essa proximidade possibilita uma maior interação entre empresas norte-americanas $e$ empresas de outsourcing da América do Sul.

\section{Outsourcing games}

Outsourcing games é uma atividade que busca subcontratar outras empresas para desenvolver jogos eletrônicos ou parte deles. Existem diversas vantagens para as empresas que contratam serviços de outsourcing. A mais óbvia delas é a redução dos custos de produção, pois a empresa contratante deixa de investir na estrutura e formação de pessoal para o desenvolvimento de serviços e produtos que não são o foco da empresa e que dificilmente gerarão diferenciais competitivos para ela. Outras vantagens, menos óbvias, porém também de grande importância, são:

- economia de tempo, pois permite que equipes trabalhem em paralelo em partes diferentes dos jogos;

- diminuição dos custos relacionados a contratação de pessoal, visto que a contratação de empresas ou profissionais liberais será por projeto e não estabelecerá vínculo empregatício;

- maior flexibilidade, não sendo necessário lidar diretamente com a burocracia e encargos relacionados a contratação e demissão de funcionários;

- maior valor, pois os funcionários da empresa poderão se dedicar mais ao desenvolvimento de tarefas que fazem parte da expertise da empresa;

- maior capacidade, visto que a empresa não estará mais restrita aos seus limites físicos e de sua equipe;

- estabilidade, pois, além de eliminar os riscos de contratação de mais pessoas para a equipe em períodos de maior demanda da empresa, o gerenciamento da equipe também é simplificado, uma vez que os gerentes têm que lidar com menos pessoas e, em decorrência, menos conflitos;

- maior especialização, pois, além de a empresa poder focar mais em sua área de expertise, também pode contratar outras empresas ou profissionais liberais altamente capacitados em qualquer parte do mundo, o que possibilita à empresa ter acesso a grande variedade de talentos e artistas sem a necessidade de contratá-los como integrantes da equipe e, consequentemente, sem a necessidade de arcar com os custos relacionados a essa integração;

- por fim, com todas as vantagens citadas, a empresa acaba obtendo meios para se tornar mais competitiva no mercado mundial (Wiegert, 2014).

No entanto, para se obterem todas essas vantagens com o outsourcing, é necessário que a empresa faça uma análise minuciosa de seus possíveis parceiros, para avaliar capacidade técnica, confiabilidade e também como a interação entre as equipes de desenvolvimento ocorrerá, a fim de garantir que os serviços contratados sejam entregues com a qualidade exigida e dentro dos prazos estipulados. Além dos cuidados relacionados com a contratação das empresas de outsourcing, é preciso também criar estratégias para lidar com algumas especificidades do setor de jogos eletrônicos, como a dificuldade na definição precisa do serviço ou produto desejado e também em cumprir com precisão um cronograma de produção, que são desafios decorrentes da natureza pouco estruturada do desenvolvimento de produtos que exigem criatividade e inspiração artística. 
O uso de ferramentas formais como documentos padronizados e agendas de desenvolvimento são, de certa forma, uma contradição ao desenvolvimento de videogames, pois, diferentemente dos softwares, que já são predefinidos com base em soluções para problemas ou necessidades, os videogames são desenvolvidos de modo mais livre (Vallance, 2014).

$\mathrm{O}$ processo de desenvolvimento de videogames é feito de maneira mais orgânica, em que cada projeto vai evoluindo de modo gradual e interativo e que, por isso, necessita de alto grau de envolvimento entre as equipes (design, programação, controle de qualidade, teste etc.). As formas de conhecimento que surgem durante o processo são de natureza mais tácita, que dificilmente podem ser expressadas em documentos e que são mais facilmente transmitidas por meio do convívio.

\section{Histórico da empresa}

A Manifesto Game foi fundada em 2005 por Vicente Vieira Filho (atual diretor de negócios), na época com 22 anos de idade, Leonardo Gesteira Costa e Marco Túlio Caraciolo Ferreira Albuquerque (atual diretor de produção), os dois últimos então com 21 anos. Todos os sócios tinham formação em ciência da computação, na Universidade Federal de Pernambuco (UFPE), e Vieira Filho fizera mestrado na UFPE em inteligência artificial para games. Apesar de Vieira Filho já ter atuado, antes da criação da Manifesto, em outra desenvolvedora de jogos eletrônicos, não teve experiências relacionadas à gestão de empresas, pois atuava na produção de jogos.

No início de suas atividades, a empresa contou com o apoio da pré-incubadora de empresas Recife BEAT - Base para Empreendimentos de Alta Tecnologia ${ }^{6}$, cuja operação é coordenada pelo C.E.S.A.R. - Centro de Estudos e Sistemas Avançados do Recife ${ }^{7}$, do agente Softex em Recife (por meio de programa que apoia a realização de ações de empreendedorismo e promove a qualidade de software) e do Centro de Informática da Universidade Federal de Pernambuco.

O histórico da Manifesto Game Studio não pode ser dissociado de seu processo de internacionalização. Desde o início de suas atividades, os sócios tinham a visão de explorar os mercados internacionais, pois o mercado brasileiro de games, em 2005, ainda era muito pequeno e pouco desenvolvido. Vieira Filho salientou:

A Manifesto sempre teve um pé muito mais no exterior do que no Brasil. Hoje em dia é que nós estamos modificando um pouco esse cenário... Mas a Manifesto, em 2005, já nasceu com a visão de atuar no mercado internacional. Em diferentes regiões do mundo, diferentes idiomas... É uma experiência muito gratificante.

Assim, desde sua criação, a empresa buscou parceiros fora do Brasil para lançar seus browser games, que foram os primeiros produtos criados na Manifesto. Trata-se de games desenvolvidos para serem jogados diretamente por meio de um navegador (browser), que foram comercializados pela empresa até 2008. Para comercializar seus jogos na internet, a Manifesto fez parcerias com portais de games on-line, que disponibilizavam seus browser games para os usuários. Encontravam-se entre seus principais parceiros grandes portais de jogos on-line como Miniclip, Kongregate e Ugoplayer.

\footnotetext{
${ }^{6}$ A pré-incubadora Recife BEAT - Base para Empreendimentos de Alta Tecnologia - foi criada pelo Centro de Informática (CIn) da UFPE em 1997, com o objetivo de estimular o empreendedorismo entre seus alunos. A meta principal é fazer com que os alunos considerem a criação de novas empresas de informática, a partir de ideias inovadoras. (Recuperado de http://www2.cin.ufpe.br/site/secao.php?s=5\&c=65).

${ }^{7}$ O C.E.S.A.R. é um centro privado de inovação, com sede em Recife, que utiliza engenharia avançada em Tecnologias da Informação e Comunicação (TICs) (Recuperado de http://www.cesar.org.br/ site/cesar/organizacao).
} 
A partir dessas experiências com os browser games é que, ao final de 2008, a Manifesto decidiu passar a produzir jogos com maior complexidade e recursos gráficos superiores, os chamados downloadable casual games, que são jogos que, para serem jogados, precisam ser baixados da internet e instalados em um computador PC ou Mac. Segundo Vieira Filho, os downloadable games "atingem um público muito específico, geralmente mulheres acima de 35 anos". O modelo de negócio utilizado para comercializar esses jogos, também via portais, é o chamado shareware, que permite o download gratuito do game por qualquer usuário, porém com restrição no tempo de uso, ou seja, após determinado período, o jogo é automaticamente travado, e o usuário é convidado a comprar a versão completa. Desse modo, o usuário tem a oportunidade de experimentar o jogo antes de realizar a compra. A empresa estimava que o mercado mundial para o modelo shareware crescesse 40\% ao ano. Em 2013, os downloadable games da Manifesto já haviam sido lançados em mais de 300 portais de games e em 11 idiomas, sendo o jogo Fruits Inc. (Anexo 1), lançado em 2009, o de maior sucesso, tendo atingido a marca de 3,5 milhões de downloads em 2013.

Durante a primeira fase - a dos browser games - a empresa tinha como alvo países ocidentais, porém, com os downloadables games, o mercado asiático também passou a ser explorado. As empresas Boonty e NextepMedia foram os parceiros que ajudaram a entrada da Manifesto nos mercados chinês, japonês e sul-coreano. Já para o mercado europeu, foi feita uma parceria com o portal Alwar, de origem russa, com forte atuação naquele continente. Na fase dos downloadable games, a Manifesto firmou parcerias com grupos maiores, como Big Fish Games, Game House, iWin, Boonty, NextepMedia e Atrativa (brasileira). Essas parcerias permitiram ampla distribuição de seus jogos, tendo uma abrangência global, porém com foco maior no mercado dos Estados Unidos.

Em 2008, a Manifesto participou de um projeto de criação de um Massively Multiplayer Online Games (MMOG) ${ }^{8}$, que combinava aprendizado a games. Em 2013, esse MMOG encontravase em funcionamento nas cidades do Rio de Janeiro e de Recife, sendo utilizado por cerca de dois milhões de alunos.

No final de 2011, os empreendedores desenvolveram um plano para a exploração do mercado brasileiro, que começava a oferecer maiores oportunidades para a indústria de jogos, graças ao momento econômico favorável que o Brasil estava vivendo. Dessa forma, em 2012, a Manifesto passou a produzir jogos visando o mercado brasileiro e também a atuar na prestação de serviços no mercado doméstico. No Brasil, a Manifesto trabalhava principalmente na linha de jogos para marcas e gameficação, em que seus principais concorrentes eram empresas como Webcore Games, Insólita Studios, Aquiris, Jynx Playware, Interama e Sioux.

A partir de 2012, quando a empresa passou a atuar também na prestação de serviços, foi necessário utilizar uma equipe interna de vendas para prospectar clientes pelo mundo, apresentando os serviços da Manifesto Game Studio. Essa prospecção era feita por meio de contatos pessoais, participação em feiras setoriais e eventos de games.

Apesar de a Manifesto ter passado a atuar com mais força no mercado interno nos últimos anos, e o mercado externo, que antes representava praticamente $100 \%$ do faturamento da empresa, ter reduzido sua participação para $10 \%$ a $15 \%$, os dirigentes da Manifesto continuavam entendendo que a atuação no mercado internacional era de absoluta importância, por vários motivos. Em primeiro lugar, a atuação internacional permitia à Manifesto permanecer atualizada sobre o que havia de mais inovador e avançado tecnologicamente no mercado mundial. Por meio de seus clientes de outsourcing, a empresa participava de projetos com grandes empresas da indústria de games mundial, como a Zynga, uma das maiores desenvolvedoras de jogos do mundo para o Facebook, e a Disney, grande referência no desenvolvimento de jogos eletrônicos. Vieira Filho declarou:

\footnotetext{
${ }^{8}$ Massively Multiplayer Online Games (MMOG) são jogos que podem ser jogados simultaneamente por grande número de jogadores on-line.
} 
Trabalhando com a Zynga, com a Disney, estamos falando de grandes empresas que são referências em todo o mundo. Então, participar de seus projetos e fazer parceria com eles, beber dessa fonte de inspiração e conhecimento, é essencial para nós nos mantermos em termos de vanguarda tecnológica, muito mais ainda no Brasil.

Em segundo lugar, a atuação da empresa no exterior era utilizada, no Brasil, como comprovação de qualidade e experiência:

Estar lá fora nos permite ter grandes cases interessantes e clientes de peso, para nos ajudar em outras áreas. Então, nas áreas em que trabalhamos aqui no Brasil, de gameficação e de games para marcas, ajuda bastante, na apresentação da empresa, para atestar nossa qualidade e experiência.

Em terceiro lugar, a desvalorização do real em relação ao dólar, em 2012-2013, também fizera com que os produtos e serviços exportados ficassem mais valorizados, tornando mais atrativas as atividades no mercado internacional. Por último, a Manifesto passou por diversos processos de aprendizagem em sua atuação no exterior. Aprendeu muito em termos de relacionamento e networking. Aprendeu sobre os principais modelos de negócios da indústria de games. Para Vieira Filho, adquirir esses conhecimentos foi de extrema importância para a empresa, tanto para a exportação de produtos quanto para a prestação de serviços: "É uma expertise extremamente válida. Acredito que poucas empresas saibam bem isso no Brasil". Assim, o aprendizado passou a ser um diferencial para a empresa, em sua atuação tanto no exterior quanto no Brasil.

A atuação internacional também alterou as percepções dos próprios funcionários da empresa, que tinham uma visão de que produtos e serviços desenvolvidos fora do Brasil eram de melhor qualidade. Ao concorrer no mercado internacional, puderam verificar que não havia diferenças significativas entre a Manifesto e outras empresas de games fora do Brasil.

\section{Características do processo de internacionalização}

Para analisar as características do processo de internacionalização da Manifesto, é preciso falar separadamente dos dois principais segmentos de atuação internacional: downloadable games e outsourcing.

\section{Downloadable games}

A comercialização de downloadable games era sempre realizada por meio de parceiros (portais de games). A Manifesto arcava com todos os investimentos de produção, e somente após a finalização do jogo buscava parceiros para a comercialização do produto. Essas parcerias traziam importantes benefícios à empresa, na visão de seus dirigentes. Em primeiro lugar, as parcerias permitiam alcançar mercados que não seriam acessáveis sem a utilização de portais de games. Por exemplo, por meio do portal Big Fish, a Manifesto já havia ultrapassado a marca de um milhão de jogos baixados. Outro benefício era a possibilidade de testar os jogos produzidos pela Manifesto antes do lançamento. Por exemplo, a Big Fish Games distribuía os jogos em versão de teste (versão beta) para mais de cinco mil jogadores de sua base de dados, usuários do portal, que se dispunham a testar jogos e, posteriormente, realizar análises e avaliações dos produtos. Essa era, então, uma oportunidade única de testar jogos para verificar possíveis falhas e também obter avaliações vindas diretamente do público-alvo, antes mesmo do lançamento oficial do jogo.

Os portais de games também prestam serviços de divulgação dos jogos de seus parceiros, pois, como têm uma quantidade de acessos muito grande de usuários, todo jogo, quando é lançado 
em um portal, fica exposto na página principal em lugar de destaque por alguns dias. Essa divulgação pode fazer com que o desenvolvedor obtenha muitos downloads e análises (reviews) positivas ou negativas dos usuários. Nesses portais também existem listas de classificação (rankings) dos melhores jogos, que são avaliados por vários critérios, tais como: quantidade de downloads e quantidade de reviews positivas. Assim, os primeiros dias de lançamento de um jogo em um portal são de extrema importância para seu sucesso. O jogo poderá continuar na página principal, em uma sessão relacionada a "melhores jogos" do portal, enquanto obtiver uma boa colocação no ranking. Em contrapartida, a Manifesto buscava desenvolver conteúdos inovadores, para serem distribuídos nos portais parceiros, ou seja, estava sempre buscando novas ideias para o desenvolvimento de jogos, não estando interessada em replicar produtos de sucesso no mercado.

\section{Outsourcing}

O foco da Manifesto em outsourcing encontrava-se na América do Norte, com maior concentração nos Estados Unidos. Os principais concorrentes eram empresas da Índia, da China e de países do Leste Europeu, cuja vantagem competitiva em relação às empresas brasileiras em geral se encontrava em aliar competência técnica a baixo custo, esse último diretamente associado a menores impostos e a uma força de trabalho mais barata. Para Vieira Filho, o outsourcing se ajustava muito bem às necessidades de alguns de seus clientes no principal mercado internacional da empresa:

A segunda área em que atuamos é outsourcing. Basicamente essa é a área que trabalha com exportação. Usamos a nossa expertise em jogos para produzir jogos para terceiros. Então nós nos posicionamos nessa área como um parceiro, sendo parte da equipe de desenvolvimento dos nossos clientes. É uma alternativa eficiente, econômica, rápida e de extrema qualidade para empresas como MightyPlay, como Zynga, nos Estados Unidos.

Para estabelecer uma relação mais forte com seus clientes, a Manifesto buscava se posicionar como parte do time, estabelecendo contato constante, passando novidades sobre novas demandas, buscando criar um relacionamento pós-venda. Dessa forma, a empresa conseguia estabelecer relações mais duradouras, não caracterizando apenas trabalhos eventuais.

No outsourcing, o maior benefício que a Manifesto proporcionava a seus clientes e parceiros era a competência (expertise), mesmo que a distância. Para superar a questão da distância física, a empresa fazia contato com seus clientes por meio de uso contínuo do Skype ${ }^{9}$, de modo a permitir que os clientes pudessem acompanhar o desenvolvimento da produção da Manifesto para ter certeza de que tudo estava sendo feito dentro das metas de qualidade e tempo previamente estabelecidas.

A Manifesto desfrutava de um grande diferencial em relação aos concorrentes internacionais do Leste Europeu, China e Índia: a localização. O Brasil está mais próximo da América do Norte e de parte da Europa (comparativamente com China e Índia). Para realizar serviços de outsourcing, é necessário que as empresas mantenham contato frequente durante a produção dos jogos, tornando a proximidade de fuso horário muito importante. Por exemplo, a diferença de fuso horário entre Recife e San Francisco, nos Estados Unidos, é de apenas quatro horas (podendo mudar um pouco de acordo com os respectivos horários de verão). Em função da pequena diferença, era possível à Manifesto manter contato em tempo real com os clientes localizados naquela cidade. Já as empresas chinesas e indianas têm mais dificuldade de comunicação, uma vez que as diferenças de fuso horário são de 10 a 12 horas. Dessa forma, grandes diferenças de fuso

\footnotetext{
${ }^{9}$ Ferramenta de comunicação com áudio e vídeo em tempo real via internet.
} 
horário também podem dificultar a construção de um relacionamento de confiança com o cliente, pois tornam mais difícil acompanhar o andamento de projetos contratados.

A prospecção de novos clientes para o negócio de outsourcing era feita principalmente por meio de participação em feiras e eventos no exterior. Na área de outsourcing, o objetivo da Manifesto era estabelecer parcerias duradouras, em que a empresa passasse a ser parte do time de desenvolvimento dos seus clientes:

O processo de venda é muito caro. É difícil fechar uma venda com um novo cliente. Então, a empresa tem que focar o estabelecimento de uma relação bem mais duradoura. Nossa ideia é estabelecer relacionamentos que tragam novos contratos com o passar do tempo. O custo de pós-venda é muito mais baixo do que o custo de aquisição de um novo cliente.

Segundo Vieira Filho, a empresa tinha mais dificuldades em conseguir parcerias de outsourcing na Europa, principalmente no Leste Europeu, pois as indústrias de games de países dessa região eram muito fortes no desenvolvimento de outsourcing games e também tinham um custo de produção de jogos eletrônicos muito próximo do custo no Brasil. O mercado europeu de outsourcing, em função disso, era menos atraente para a Manifesto. Todos os serviços eram desenvolvidos com base em contratos formais com parceiros e clientes. Nos contratos, eram claramente definidos todos os termos que explicitavam direitos e deveres das partes (contratada e contratante), além dos cronogramas de desembolsos e os calendários de execução dos projetos.

A maior demanda do mercado internacional atendida pela Manifesto era a de outsourcing para desenvolvimento de downloadable games, tanto para dispositivos móveis como para Facebook. Em 2013, o principal cliente da Manifesto na área de outsourcing era a MightyPlay, que prestava serviços para diversas empresas nos Estados Unidos. Foi por meio dessa empresa que a Manifesto conseguiu conquistar clientes diretos naquele país, como Disney e Sea World.

\section{$\underline{\text { Receita (monetização) }}$}

A empresa faturava no mercado internacional de duas formas: royalties share e serviços. No passado, a empresa experimentou vários outros modelos de monetização, mas acabou por fixar-se nesses dois. Na modalidade royalties share, a empresa recebia uma porcentagem sobre as vendas de seus downloadable games, sob a forma de royalties. O processo de precificação dos downloadable games era totalmente feito pelos portais de games parceiros da Manifesto. Normalmente esses preços ficavam na faixa de 6,99 a 15 dólares, de acordo com a versão do jogo, standard ou premium, podendo também variar de um portal para outro. Tulio Caraciolo explicou, em uma entrevista à imprensa:

Não faturamos por conta do produto, mas sim pelos valores pagos pelos consumidores para baixá-lo. [...] A receita é dividida entre os desenvolvedores e os distribuidores. Se o jogo ganha popularidade, todos ganham, se o público não gosta, a desenvolvedora amarga o prejuízo. ${ }^{10}$

Já na prestação de serviços, os negócios eram fechados nos formatos convencionais para a realização de um serviço, em valores fixos previamente acordados. Os preços dos serviços de outsourcing eram fixados com base nos custos, nos esforços envolvidos e no escopo do projeto.

\footnotetext{
${ }^{10}$ Simões, K. (2012, Junho 29). Mercado de games abre caminhos no exterior. Valor. Recuperado de http://www.valor.com.br/especiais/2732562/mercado-de-games-abre-caminhos-no-exterior
} 


\section{Problemas enfrentados pela empresa para a internacionalização}

Um problema que preocupava os dirigentes da Manifesto Game Studio, característico do setor de atuação da empresa, era a falta de informação sobre o mercado e, particularmente, sobre os usuários finais de seus produtos.

Quando a Manifesto começou suas atividades, produzindo browser games, a empresa tinha poucas relações com seus parceiros e com os usuários finais dos seus jogos e, por isso, recebia pouco retorno relacionado ao nível de satisfação de parceiros e clientes. Com a passagem da produção de browser games para downloadable games, a Manifesto sentiu a necessidade de estabelecer relacionamentos mais diretos com seus parceiros, e, para isso, os dirigentes da empresa passaram a fazer visitas a seus escritórios, com o objetivo de obter e transmitir mais confiança e, como resultado, fechar mais contratos de distribuição e obter maior feedback. No entanto, a comercialização dos downloadable games por meio de portais parceiros apresentava alguns problemas referentes à falta de informações sobre os usuários dos games da empresa. A Manifesto recebia apenas relatórios referentes às vendas, ou downloads dos seus jogos, ou seja, ela não recebia informações relativas aos usuários, tais como a forma como os usuários jogavam, onde jogavam, os horários mais utilizados para jogar etc. Na visão dos dirigentes, tais informações seriam essenciais para uma estratégia de atuação mais eficiente. Apesar da falta de informações sobre os usuários de seus produtos, a empresa dispunha de ampla informação sobre o mercado de games na América do Norte e na Europa, que se encontrava disponível. Mais difícil era obter informações sobre os mercados latino-americanos, que, no entanto, poderiam ser muito úteis para identificar oportunidades de negócio no Brasil e em outros países da região.

Além da falta de informação, a Manifesto precisava lidar com diversos problemas na comercialização de seus produtos e serviços no exterior, que variavam desde a falta de evolução das parcerias internacionais até questões relativas à tributação. Um problema na parceria com os portais de games que comercializavam os jogos da Manifesto era a percepção de a política de parceria com os portais de games não evoluir, ou seja, uma parceria feita com uma nova empresa recebia o mesmo tratamento de parcerias já estabelecidas há anos, não havendo qualquer diferenciação.

Outra barreira para a expansão das vendas internacionais eram os altos tributos cobrados, principalmente quando os jogos eram exportados para os Estados Unidos, principal mercado externo da Manifesto e também o maior do mundo. Para a exportação de jogos na forma de produto, os impostos pagos aos Estados Unidos, mais os impostos pagos no Brasil, inviabilizavam a maior parte dos negócios e, consequentemente, reduziam em muito a possibilidade de expansão dos negócios de games nesse país, pois as margens de lucro ficavam pouco atraentes. Pelo acordo de tributação bilateral existente entre Brasil e Estados Unidos, 30\% dos royalties que as empresas de games brasileiras ganhavam com vendas nos Estados Unidos eram retidos pelo governo americano. Como a divisão de receita entre a Manifesto e os portais de games era da ordem de $50 \%$ a $60 \%$ para os portais e de $50 \%$ a $40 \%$ para a Manifesto, após essa divisão, $30 \%$ dos royalties da Manifesto eram retidos pelo governo americano a título de taxação, chegando apenas $28 \%$ do valor da receita dos jogos ao Brasil. Em seguida, a Manifesto pagava no mínimo 4,88\% de impostos sobre o montante recebido, podendo variar de acordo com a forma de declaração do lucro. Ao final, dos $100 \%$ da receita de vendas dos jogos nos Estados Unidos, a Manifesto recebia, na melhor das hipóteses, $23,12 \%$.

Com relação ao negócio de outsourcing, o principal problema era o custo de produção no Brasil, devido à alta carga tributária e às contribuições trabalhistas, que, em muitos casos, podiam ultrapassar $100 \%$ do valor do salário. Os tributos geravam custos muito altos e, como consequência, tornavam a indústria de games brasileira menos competitiva do que a de outros países, como os do Leste Europeu, China e Índia. 
Outro problema evidenciado por Vieira Filho era a desconfiança - até mesmo o preconceito - por parte de parceiros internacionais, com relação à capacidade técnica e ao profissionalismo de empresas de games da América Latina em geral:

Muitos clientes com quem entramos em contato já trabalharam com empresas chilenas ou argentinas. Acho que nenhum havia trabalhado com empresas brasileiras, mas em todos os casos eles diziam que não tinham tido uma boa experiência. Ou o prazo estourava, ou a entrega não era feita, ou o developer queria mais dinheiro porque o estúdio não conseguia terminar etc.

Para contornar essa dificuldade, a Manifesto buscou construir um histórico de serviços internacionais prestados e intensificou esforços para entregar seus projetos dentro do prazo acordado com seus clientes. Além disso, a direção da Manifesto percebeu que conseguiria maior receptividade dos parceiros por meio de reuniões presenciais, e não somente pela internet. Assim, os dirigentes consideravam que havia a necessidade de presença física constante fora do Brasil, principalmente nos Estados Unidos, por meio de uma pessoa ou de um escritório. Mas, como isso ainda não era viável para a Manifesto, tentava-se preencher essa lacuna por meio de participação em feiras e eventos nos Estados Unidos, prospectando e promovendo a empresa.

A Manifesto já havia participado de ações com Apex-Brasil ${ }^{11}$ e Softex. Nos anos de 2012 e 2013, a empresa foi beneficiada por uma iniciativa conjunta da Apex e da Softex para promover as exportações. Nessa iniciativa, as instituições custeavam parte das despesas de participação na feira Game Developers, em San Francisco, nos Estados Unidos, sendo os custos relativos ao espaço na feira e à montagem dos estandes pagos pela iniciativa, enquanto os custos com passagem e hospedagem eram absorvidos pelas próprias empresas, como contrapartida. A empresa considerava aumentar sua participação em feiras internacionais, de duas para três por ano, tanto com o propósito de promover seus produtos e serviços, como de estabelecer agentes na Inglaterra e nos Estados Unidos para representarem a empresa. Na Inglaterra, já estava em curso a primeira tentativa e, nos Estados Unidos, a empresa estava buscando um representante. A Manifesto utilizava também redes sociais, como Linkedin, para a prospecção, a divulgação do seu site e a ampliação de sua network.

\section{Perspectivas}

A grande maioria dos projetos realizados pela Manifesto foi iniciada a partir dos esforços diretos da empresa na busca por clientes e parceiros, ou seja, foram poucos os casos em que a Manifesto foi procurada por um cliente. Essa questão parecia fundamental aos dirigentes da empresa, indicando claramente a necessidade de desenvolver um plano de médio prazo, que permitisse à empresa (i) aumentar sua visibilidade junto a clientes internacionais, (ii) melhorar seus processos de prospecção de novos clientes, (iii) aumentar seu conhecimento sobre o comportamento dos usuários de downloadable games, e (iv) desenvolver seu relacionamento com clientes de outsourcing.

\footnotetext{
${ }^{11}$ Agência Brasileira de Promoção de Exportações e Investimentos.
} 
A INTERNACIONALIZAÇÃO DA MANIFESTO GAME STUDIO

Gil Barreto de Goes, Jorge Brantes Ferreira

\section{Anexo 1}

Games desenvolvidos pela Manifesto Game Studio

Fruits Inc.
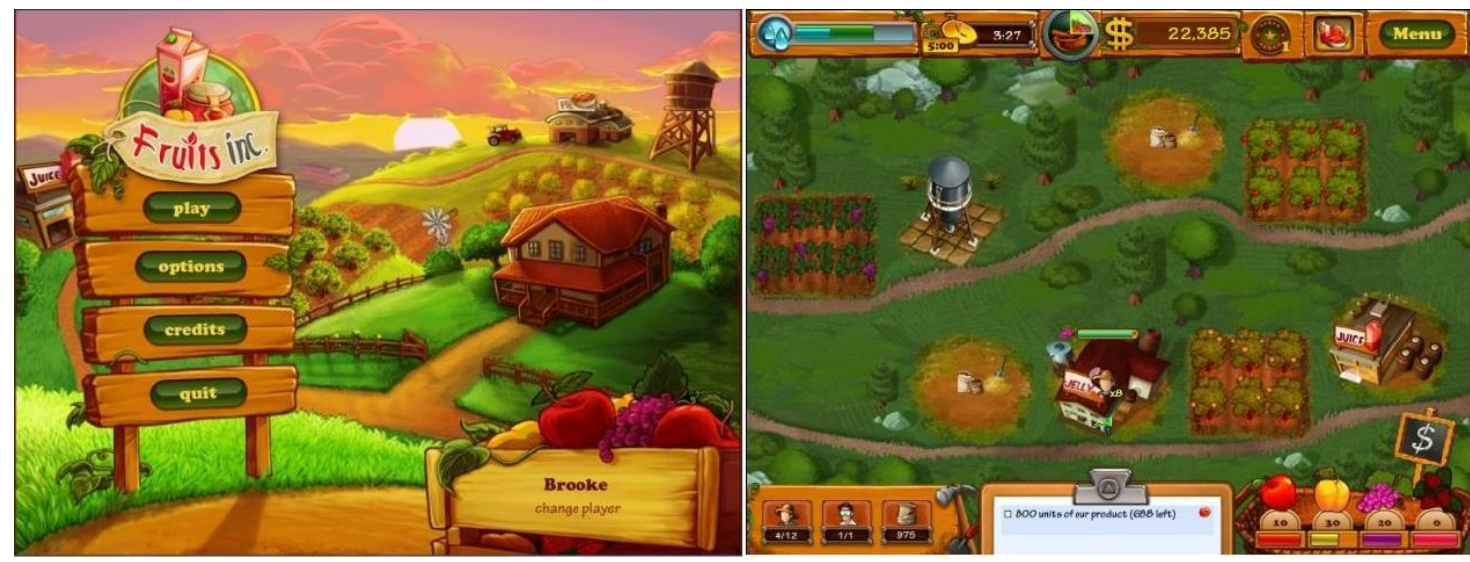

Merlin Christmas
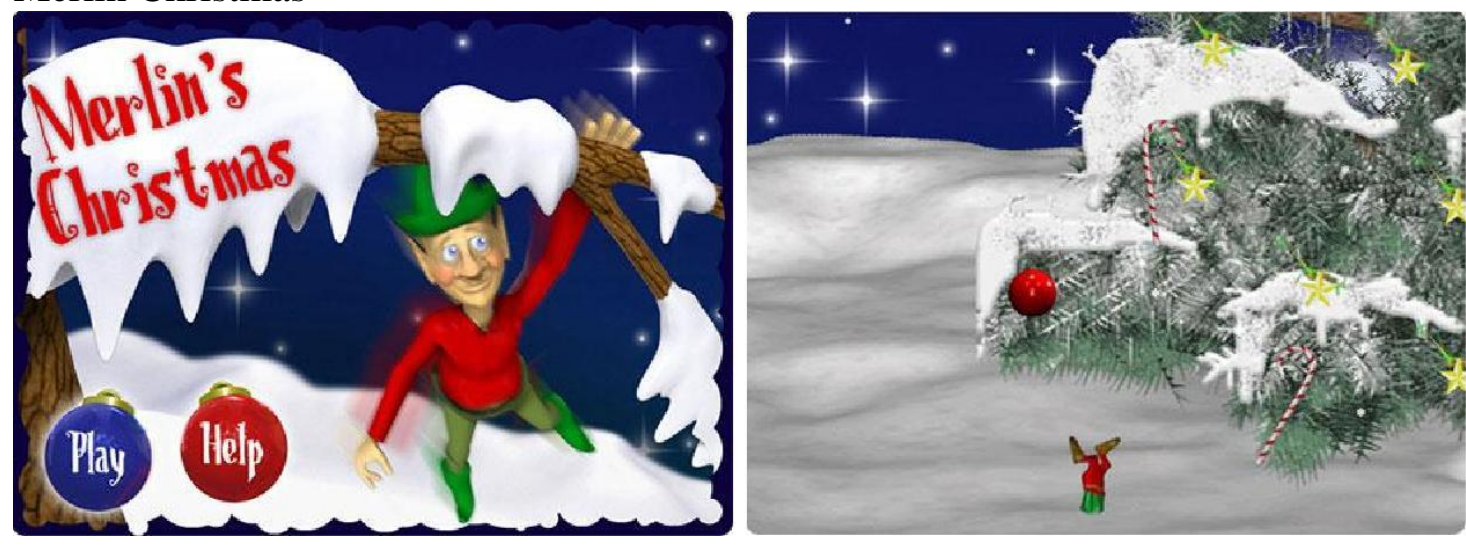

\section{Pizzaiolo}
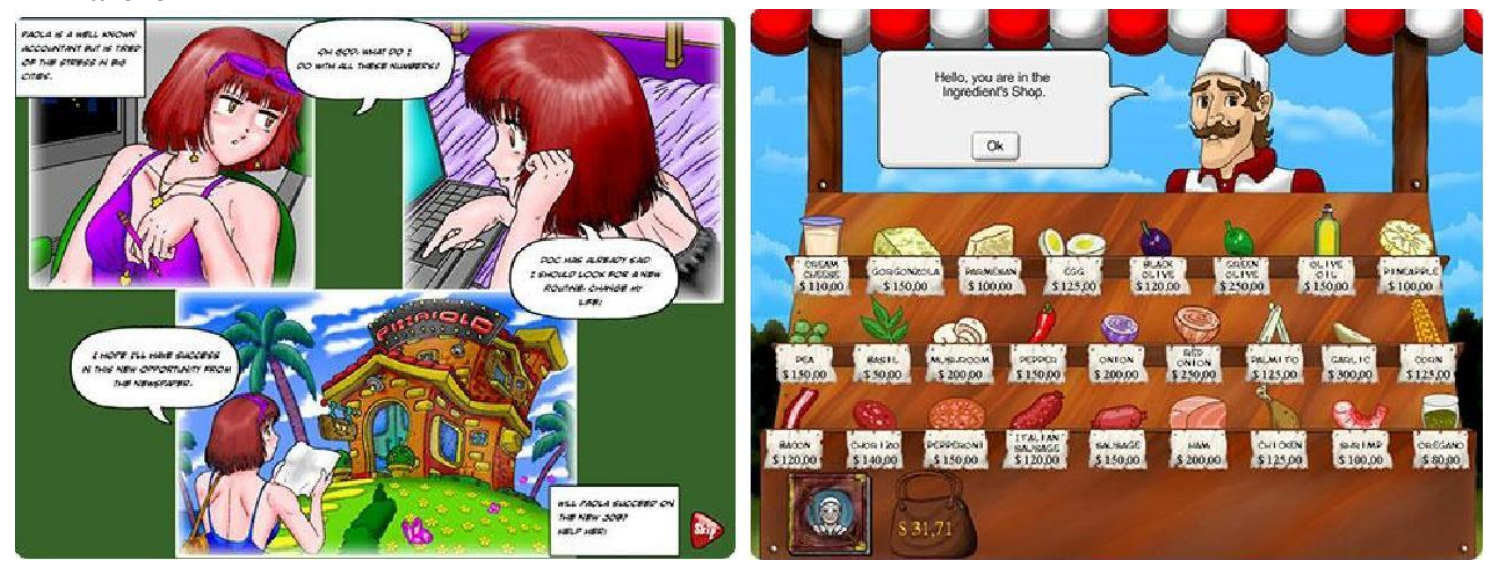
A INTERNACIONALIZAÇÃO DA MANIFESTO GAME STUDIO

Gil Barreto de Goes, Jorge Brantes Ferreira

\section{Anexo 2}

Evolução das receitas de games nos três principais mercados mundiais - EUA, Japão e China

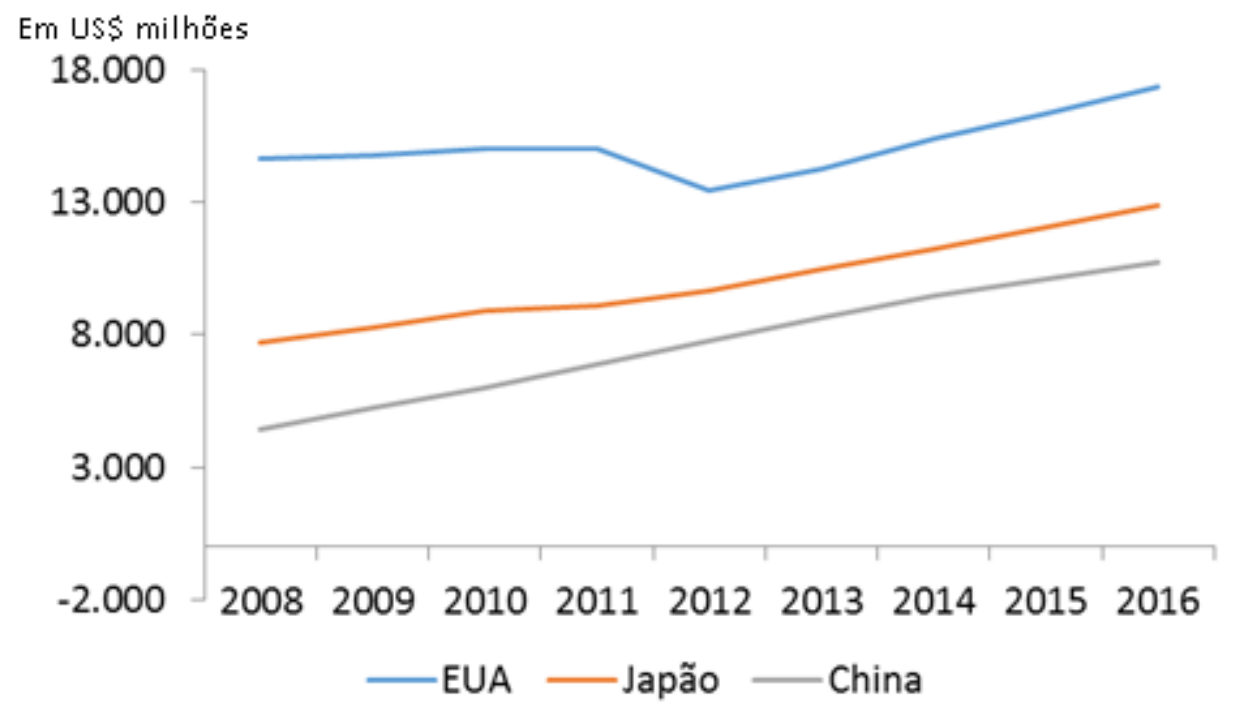

Nota: Projeção para os anos de 2012 a 2016.

Fonte: PwC (2013). Global entertainment and media outlook: 2013-2017 